\title{
Criação coletiva e processo colaborativo: algumas semelhanças e diferenças no trabalho dramatúrgico
}

\author{
Adélia Nicolete
}

"Quando será que essa dramaturgia vai ficar pronta? Quando será que vamos parar de reescrever esta cena? Algum dia esse roteiro vai ficar bom? O prazer de trabalhar com dramaturgos antigabinetes, antitorres-de-marfim. Generosos e arrojados. Sem preguiça de ouvir as necessidades que nascem na sala de ensaio, sem pudor de jogar seu texto fora se a cena assim o pedir. Dramaturgos que abdicam da eternidade em prol de uma escrita tão fugaz e temporária como a dos atores e diretores."

Antônio Araújo

té os princípios do século XX, era impensada uma colocação como essa, feita pelo diretor do Teatro da Vertigem em um texto em que ele pretendeu reportar, à maneira da escrita surrealista, o denominado processo colaborativo de trabalho nos espetáculos da Trilogia Bíblica do grupo. ${ }^{1}$

Durante muito tempo o texto foi considerado o elemento mais importante do teatro e o autor teve o domínio de conteúdo, forma e sentido. Dessa maneira, como encenar uma peça que ainda não fora escrita por completo? Para que dar ouvidos a atores, se eram encarados como simples emissores do texto? Dar voz ao diretor, se sua missão era cumprir 'fielmente' as prescrições de um autor que, na quase totalidade dos casos, escrevia a peça concentrada e solitariamente, acalentando o sonho nada secreto de ser eternizado pela literatura?

Têm pouco mais de um século os primeiros questionamentos da autoridade do texto e do autor. Os diretores foram assumindo cada vez mais sua posição como criadores do espetáculo, chegando mesmo a 'depor' o texto em nome da encenação, e o ator também pôde conquistar uma outra posição que não a de mero executante de idéias alheias - tanto que, por volta dos anos 1960, chegou-se a afirmar o corpo contra o texto. Numa época em que ao ator começou a caber grande parcela da criação, a equipe como um todo ganhou destaque e passou a se encarregar da elaboração do espetáculo, desde a idéia original até a finalização. Havia, segundo

Adélia Nicolete é dramaturga e roteirista. Licenciada em Artes Cênicas, é especialista em Educação e mestranda em Teoria e História do Teatro pela ECA/USP.

1 Embora a prática aqui descrita eventualmente possa ser denominada de outras maneiras, optou-se pelo termo "processo colaborativo" tal como adotado pelo Teatro da Vertigem. Antônio Araújo vem coordenando cursos de direção e núcleos de pesquisa na Escola Livre de Teatro de Santo André, entre outros locais, onde propõe uma investigação sobre esse procedimento desde 1999, período em que pude iniciar pesquisa e prática de dramaturgia em processo colaborativo que se estendem até o presente momento. 
Pavis, um "clima sociológico" favorecendo que o autor, antes individual, passasse a corresponder ao coletivo do grupo ${ }^{2}$ - ganhando destaque a chamada criação coletiva, vista por muitos como a precursora do processo colaborativo. Sílvia Fernandes afirma que há semelhanças entre os dois procedimentos, mas que eles não chegam a se confundir (Fernandes, 2002, p. 36). O fato é que em ambos o dramaturgo desceu, finalmente, de sua torre de marfim e foi para a sala de ensaio.

No Brasil, os grupos aumentaram em número, contrapondo-se aos chamados "elencos" - artistas reunidos para uma determinada montagem e que, ao final da temporada, dispersavam-se, indo em busca do próximo trabalho. Redescobriu-se o aspecto ritual e coletivo do teatro, com franca inspiração em Antonin Artaud, Jerzy Grotowski e no grupo Living Theatre, e o aspecto lúdico despertado pelos jogos e improvisações. No aspecto político, uma produção eminentemente grupal representava uma espécie de 'democratização' da arte: ela era criada por e para as massas, estimulando a produção cooperativa dos artistas envolvidos, que puderam libertar-se da figura do produtor e, conseqüentemente, da necessidade de se fazer um teatro dito comercial.
Ganharam destaque, a partir dos anos 1970, as produções coletivas dos grupos Asdrúbal Trouxe o Trombone, Ornitorrinco, Mambembe e Pod Minoga, que inspiraram muitos outros grupos pelo país. ${ }^{3} \mathrm{O}$ dramaturgo Luís Alberto de Abreu, em entrevista realizada em janeiro de 2002 pela autora, reflete que o aumento do número de grupos, característico desse período, resultou numa busca pelo desenvolvimento de novos temas, não encontrados na dramaturgia já constituída. E se os textos não existiam, era preciso criá-los e os grupos se propuseram a isso. Nesse tipo de processo, que não é assinado nem pelo dramaturgo nem pelo encenador individualmente, mas pelo grupo, o texto (quando existe) é fixado depois de um período de ensaios baseados em improvisaçôes, onde cada participante propõe encaminhamentos, soluções, modificações - a partir de um tema ou tendo o tema definido no decorrer das pesquisas. Em geral, o ator é o elemento central do processo e, a partir de suas improvisaçôes, podem surgir, além do texto, idéias de cenários, figurinos, luz etc. ${ }^{4}$

A partir desses aspectos, podemos traçar um primeiro paralelo entre esse tipo de produção e o processo colaborativo, que também corresponde a uma investigação coletiva - que

2 "Brecht definiu tal trabalho coletivo como socialização do saber; mas pode-se concebê-lo igualmente como colocação em discursos de sistemas significantes na enunciação cênica: a encenação não representa mais a palavra de um autor (seja este autor dramático, encenador ou ator), porém a marca mais ou menos visível e assumida da palavra coletiva." (Pavis, 2000, p. 80)

3 Para um aprofundamento nos procedimentos e na trajetória de cada um desses grupos, recomendamos a leitura da obra de Sílvia Fernandes, Grupos teatrais: anos 70 (2000), principal referência sobre criação coletiva para a redação do presente artigo.

4 Era esse o padrão, porém outras equipes encontraram caminhos diferentes, como, por exemplo, o Grupo Forja, do Sindicato dos Metalúrgicos de São Bernardo do Campo e Diadema, ao criar seu espetáculo Pensão Liberdade no fim dos anos 1970. O dramaturgo Tin Urbinatti (1981) relata que, depois de pesquisar entre a comunidade operária os elementos que gostariam de ver encenados (situação política do país, corrupção, desmandos etc.), o grupo efetuou estudos e decidiu pelo tema (ausência de liberdade). Definiram-se, coletivamente o ambiente da pensão e os personagens e, em seguida, o texto foi sendo construído, cena a cena, diálogo a diálogo, amparado por pesquisas históricas, políticas e de prosódia. Dessa maneira, primeiro surgiu o texto - coletivo - e só depois a encenação. 
tende a se aprofundar na medida em que o grupo permanece o mesmo ao longo dos trabalhos. O Teatro da Vertigem, entre outros grupos, vem há dez anos propondo-se a refletir sobre a realidade e a criar seus espetáculos como fruto da colaboração entre atores, dramaturgo e encenador, agregando, também, outros profissionais da cena. Sua prática, à maneira coletiva, pressupóe um ator que é também autor e performer, e que tem liberdade "de participar em outras áreas de criação, como dramaturgia, figurino, som, iluminação, cenografia, assim como no material já criado anteriormente por um companheiro em sala de ensaio, somando soluções em infinitas possibilidades" (Rinaldi, 2002, p. 45).

E, à semelhança dos grupos de criação coletiva, a primeira montagem do Teatro da Vertigem, Paraíso perdido, ocorreu de maneira colaborativa justamente pelo fato do grupo não encontrar um texto teatral que correspondesse aos anseios da totalidade da equipe. Diante da ausência desse pré-texto, fez-se um levantamento de temas que resultou na questão do sagrado. Antônio Araújo sugeriu a obra $O$ paraíso perdido de Milton que, depois de lida pelo grupo, motivou-os a investigar aquele universo composto por Adão, Eva, Satanás e a perda do paraíso (Andrade, 2000, p. 171). Os outros processos foram semelhantes no que tange à ausência de um pré-texto, ao estímulo de continuar trabalhando com o sagrado e de criar a dramaturgia ao longo do processo, tarefa para a qual foi convidado um dramaturgo para cada um dos trabalhos.

Isso leva a outro ponto desse paralelo entre os dois procedimentos de criação do espetáculo: a figura do dramaturgo. Os grupos que se dedicavam à criação coletiva, em sua maioria, não dispunham de alguém designado especificamente para a elaboração do texto e os que, eventualmente, assumiam esse papel, tinham uma função mais organizadora que autoral. $\mathrm{O}$ mais comum era que o grupo assumisse também coletivamente a organização do material e, em grande parte dos casos, a direção do trabalho. Quando havia um responsável pela dramaturgia, esse não deveria imprimir sua marca pessoal ou seu 'estilo'; ao contrário, o texto precisava ter a marca do coletivo; os componentes queriam ver a sua parcela identificável no todo - daí a impressão de 'colcha de retalhos' que a criação coletiva podia nos dar. ${ }^{5}$

No caso do grupo carioca Asdrúbal Trouxe o Trombone, Hamilton Vaz Pereira atuou, desde o primeiro trabalho, como "uma espécie de elemento depurador da criação" (Fernandes, 2000, p. 38) Era ele quem propunha exercícios e jogos, improvisações que estimulassem a criação de cenas e situaçóes. No período de preparação da peça Trate-me leão, após a seleção de fragmentos por parte da equipe (contos, letras de música, cenas de filmes, poemas, que traduzissem aquilo sobre o que queriam falar), $\mathrm{Ha}$ milton anotou os ingredientes principais e, a partir desses núcleos de assunto, iniciou a redação de pequenas cenas, que ia submetendo à aprovação do grupo. Feito esse primeiro esboço, escritores, fotógrafos e músicos, amigos da trupe, foram convidados a escrever outros quadros da peça, numa experiência de inserção da sua comunidade cultural no processo criativo. $\mathrm{Na}$ montagem da peça Aquela coisa toda, todos os participantes dirigiram algumas cenas, propondo diversos caminhos e, em 1979, depois de alguns meses debruçado solitariamente sobre o material, Hamilton propôs uma estrutura dramatúrgica.

Um outro exemplo é o grupo paulista Pod Minoga, que atuou de 1972 a 1980 e que não contava com um dramaturgo ou alguém que organizasse e desse unidade ao material surgido nos improvisos. As quatro peças curtas da

5 O que não significa que no processo colaborativo não possamos identificar, aqui e acolá, momentos que tenham a marca pessoal de quem os criou, seja ator, diretor ou dramaturgo. 
fase amadora do grupo não tinham sequer um texto escrito - os atores variavam um pouco a cada espetáculo, dependendo da sua inspiração momentânea. Tinham apenas um roteiro básico, que procuravam manter inalterado, e que era composto por uma sequiência de ações que os atores haviam memorizado durante os ensaios e que ia se acomodando no decorrer das apresentações, no contato com o público. Só em 1978, já atuando profissionalmente, é que anotaram o texto de Salada Paulista, uma exigência da censura.

Já o processo colaborativo requer, desde o início, alguém responsável pela assinatura de um texto, em pé de igualdade com os responsáveis pela direção, interpretação e outros setores da produção. Tudo que é produzido em sala de ensaio é devidamente apreciado, discutido e registrado pelo dramaturgo até um ponto que se julgue 'satisfatório' quanto aos propósitos originais. ${ }^{6} \mathrm{O}$ dramaturgo, que pode ou não estar presente em tempo integral, intervém com idéias, encaminhamentos e sugestôes de texto/cena, transforma as sugestóes dos atores - que, muitas vezes, podem não ter estrutura dramatúrgica - em núcleos de ação; elabora a síntese de elementos que se repetem ou que são similares; insere dados, promove a unidade textual, sem as 'amarras' da quase obrigatoriedade de conservar o material individual criado pelos atores o que, veremos, é uma das principais características da criação coletiva.

Mesmo que em boa parte do processo ele se assemelhe à criação coletiva - improvisações, discussões etc. - quando chega a hora da unidade necessária ao texto, quem assume é o dramaturgo. É ele quem tem maiores condições de identificar lacunas, desequilíbrios e falhas, e saná-los; promover realocações, alterações, esclarecimentos, assinando como seu esse arranjo dramatúrgico. Luís Alberto de Abreu, responsável pelo texto de O livro de Jó, segunda montagem do Teatro da Vertigem, afirma que não importa se o ator escreveu partes do texto, se escreveu cenas, se o diretor escreveu ou propôs açōes, quem deve organizar tudo isso é o dramaturgo.

Porém, essa responsabilidade não garante a ele o status de autor único. Segundo Antonio Araújo, no processo colaborativo a autoria é compartilhada por todos. O dramaturgo assina um texto cheio de interferências e contaminaçôes dos outros componentes da equipe que, por sua vez, também tiveram seu trabalho igualmente contaminado. (Andrade, 2000, p. 178). E é novamente Abreu, um dos pioneiros na dramaturgia colaborativa, quem ressalta que, apesar disso, não há o esmaecimento da figura do dramaturgo; ao contrário, o seu trabalho tornase mais desafiador porque o material criativo é muito maior do que o levantado "em gabinete". Desafios técnicos, estéticos e éticos. Muitas vezes ele está conduzindo a dramaturgia por um caminho que terá de ser descartado em função de elementos novos que forem inseridos. Assim, o dramaturgo tem de colocar a sua criação num outro patamar, acima de vontades pessoais tão características da antiga soberania do texto/autor, e modificar o que havia feito em nome de uma outra geometria - ou fazer prevalecer a sua opinião ao restante da equipe caso esteja convicto.

Nesse sentido, Sérgio de Carvalho, responsável pela dramaturgia de Paraíso Perdi$d o$, afirma que o Teatro da Vertigem reinventou a criação coletiva dos anos 1970 "sem democratismo e com maior rigor de método”

6 Sobre o trabalho colaborativo, por ele chamado de work in process, e sobre a atuação do autor em sala de ensaio, recomenda-se a leitura de Rubens A. Rewald, Caos/dramaturgia (1998), onde se propõe a figura do autor-espectador. Chegou-se a esse termo a partir dos estudos da obra Universo da criação literária, em que P. Willemart comenta a existência de um autor-escritor e de um autor-leitor (referentes à literatura), segundo estudos de A. Grésillon e J.-L. Lebrave. Rewald propõe um autor-espectador, próprio da arte teatral, que é acrescentado aos dois leitores anteriores. 
(Carvalho, 2002, p. 55). Isso leva a outro ponto importante, também relativo à dramaturgia: a contribuição de cada um e a seleção dessa contribuição com vistas ao produto final.

Retomando o exemplo de Trate-me leão, do Adrúbal - e o fazemos por parecer comum a um sem número de outros grupos - o andamento dos ensaios é descrito por Sílvia Fernandes como um momento de plena liberdade de expressão, onde os criadores podiam se manifestar integralmente. "Qualquer contribuição valia. Um gesto, uma frase, um pulo melhor executado ou uma piada recebiam igual tratamento, pois os critérios de valor eram muito variáveis." Essa liberdade devia-se, em grande parte, à inexperiência da maioria dos atores, pois "não existiam parâmetros técnicos nem tampouco métodos de trabalho que definissem critérios estéticos ou procedimentos criativos. Tratava-se de aprender fazendo, pelo sistema de ensaio e erro, aproveitando descobertas anteriores para abrir caminho a novos achados que, pela somatória, criavam um modo particular de construir o espetáculo" (Fernandes, 2000, p. 52). E o texto final, por ter sido criado coletivamente, contemplava todas as contribuições sob a forma de uma grande colagem de fragmentos, resultando muitas vezes em espetáculos longos, prolixos, com certa redundância, o que dava uma impressão caótica e "suja" - como que denunciando o processo. ${ }^{7}$

Esse dado denuncia uma situação por que praticamente todos os grupos que produziram via criação coletiva passaram: o perigo do des- controle. O material levantado durante os ensaios era muito grande e, "no processo de enxugamento dos textos, interfere a ligação afetiva embrionária que une os criadores ao fruto de seu trabalho exaustivo, que às vezes supera um ano de preparação. Em princípio, ninguém quer tirar nada da peça, pois tudo está intimamente ligado à vivência de cada um. Cada corte é encarado como uma perda, um desejo que não encontrou espaço de realização" (Ibid., p. 226).

Os procedimentos criativos do processo colaborativo não diferem muito da criação coletiva. As variaçôes ocorrem, muitas vezes, no que tange às intervenções e aos estímulos da direção e da dramaturgia - que pode periodicamente criar, recriar e alterar propostas de cenas a serem (re)experimentadas pelos atores durante os ensaios. E nada impede que cenas inteiras criadas pelos atores estejam presentes quase que integralmente no espetáculo.

Quanto ao material levantado, à semelhança da criação coletiva, geralmente é vasto, daí a igual necessidade dos cortes. É Antônio Araújo quem ilustra essa fase: "a necessidade dos fechamentos, das sínteses, dos cortes. A sangria dos cortes. Por que somente o texto do outro é que precisa ser cortado? Por que somente a cena do outro é que é prolixa?" (Araújo, 2002, p. 84) E é ele quem aponta a necessidade, nesse momento, de "sacrificar o cordeiro do ego" (sem sacrificar a individualidade artística) para que se evite o que ele chama de "democratite", onde as contribuições de cada um são eqüitativamente

A esse respeito Abreu comenta que existe uma similaridade com o processo colaborativo, já que nele há também uma renúncia à precisão característica da dramaturgia aristotélica - onde o texto é pensado tão somente pelo dramaturgo, que tem controle maior sobre o ritmo, o tratamento do personagem, a trama. Renúncia em benefício de algo que seja mais interessante para o espetáculo porque há uma fusão da criação de todos: determinada cena pode destoar do contexto, mas está presente porque é boa, ganhou o direito de estar ali, embora não esteja tão bem conectada. O espetáculo colaborativo não é tão apolíneo, mas salta no palco o dionisíaco e na relação com a platéia isso é o que mais impressiona. Segundo Abreu, aí está a diferença, por exemplo, de quando se lê um texto escrito no processo colaborativo e quando se assiste ao espetáculo. $\mathrm{O}$ texto talvez não pareça tão interessante, mas o espetáculo, muitas vezes, o é. E, por motivo semelhante, a grande maioria dos textos criados coletivamente não foi publicada, pois é praticamente impossível dissociá-los das montagens. 
selecionadas em detrimento da unidade e do objetivo do espetáculo.

No processo colaborativo, o dramaturgo é um dos principais responsáveis pela seleção do material - sempre junto com a equipe. Nesse momento, diz Abreu, ele deve saber que é criador do espetáculo e não apenas criador de um texto que vai permanecer; deve buscar não o texto escrito da melhor forma, mas, muitas vezes, decidir riscar uma página que está extremamente bem escrita, em função de uma eficiência maior do espetáculo em relação ao público. Outra coisa importante que o dramaturgo deve aprender é trabalhar em conjunto, pois o processo requer paciência e, muitas vezes, discussões acirradas, já que, segundo Abreu, o melhor processo colaborativo é o de relações fortes. No fim, o que deve prevalecer, para todos, é o produto final - sua coerência, seu atendimento aos anseios originais da equipe. E quem participa desse processo sabe que, muitas vezes, isso implica em abrir mão de criaçõos preciosas, sejam atores, diretores ou dramaturgos.

Foi dito anteriormente que no processo colaborativo, o dramaturgo encontra-se em pé de igualdade com os demais artífices da cena. Vale dizer que isso difere significativamente da 'igualdade' de funções característica da criação coletiva. Se, nessa, todos participavam ativamente de todas as funções criativas e até da manufatura dos materiais de cena e de divulgação, assinando coletivamente as criaçôes, naquele há uma limitação, ainda que virtual, de funções, uma centralização maior de competências: cada um trabalha e responde pela sua função - o que não impede que haja uma imbricação ou uma fusão de interesses e especialidades em nome da construção do espetáculo.

Os limites de atuação no processo colaborativo são tênues. Há momentos em que os atores e a direção apresentam questionamentos e soluçôes relativos à dramaturgia; ou em que o dramaturgo propõe uma solução cênica ou conduz a interpretação do atores. Provoca-se, às vezes, uma sensação de estar ultrapassando a própria área e invadindo a competência do outro, o que gera uma tensão criativa - já presente pela insegurança provocada pela ausência de um pré-texto. ("Quando será que essa dramaturgia vai ficar pronta? Quando será que vamos parar de reescrever esta cena? Algum dia esse roteiro vai ficar bom?"). Na verdade, como assinala Miriam Rinaldi, em nome dos atores do Teatro da Vertigem, o que parece existir "é a expressão do diálogo artístico, num jogo de complementaridade" (Rinaldi, 2002, p. 46). Cada grupo acaba encontrando a sua própria maneira de lidar com isso, seja estabelecendo regras, acomodando ou discutindo - mas o fato é que as 'invasões' existem e são parte indissociável do processo. E para que haja um aprofundamento cada vez maior desse tipo de trabalho, o dramaturgo de $O$ livro de Jó recomenda o estudo de cada uma dessas áreas por parte da equipe. Para ele é importante que o dramaturgo entenda também de direção e de interpretação, que os atores e diretores estudem também dramaturgia, tudo em nome do compartilhamento e da complementaridade apontada por Rinaldi e que fazem com que cada 'ultrapassagem de limite' seja o mais apropriada possível e aconteça em benefício do espetáculo.

E é em benefício do espetáculo que deve ocorrer, no processo colaborativo mais ainda do que ocorria na criação coletiva, a relação dramaturgo-diretor. $\mathrm{O}$ dramaturgo daquele tipo de processo tem maior autonomia em relação ao texto, sua relação com o diretor é praticamente de igual para igual (digo "praticamente" pois a assinatura geral do espetáculo é sempre do encenador). Ambos analisam o material surgido em sala de ensaio na tentativa de compreender o andamento do processo e a melhor maneira de encaminharem, juntos, o trabalho levantado pelos atores para que atinjam determinado ponto. Nesse sentido, o dramaturgo funciona também como diretor - assim como, ao ter suas sugestôes de texto vivenciadas pelos atores, estes sugerem coisas e atuam, nesse momento, como 'dramaturgos'.

$\mathrm{Na}$ criação coletiva, essa integração diretor-dramaturgo era mais tênue, até porque o 
texto nascia do conjunto e a atividade do responsável pela dramaturgia era mais de alinhavar, juntar e adequar os materiais individuais num todo interessante e coerente - mesmo dentro de uma incoerência proposital. Em alguns casos, as funções de dramaturgo/organizador e diretor/coordenador eram desempenhadas pela mesma pessoa, o que garantia em si uma integração no encaminhamento dos trabalhos ou, como já foi dito, o próprio grupo se encarregava de escrever e dirigir, diluindo as especificidades.

$\mathrm{Na}$ tentativa de concluir essa breve reflexão sobre alguns dos procedimentos contemporâneos do dramaturgo junto à cena, é importante lembrar que não há, nem nunca houve, um padrão a ser seguido no que se refere à criação coletiva ou ao processo colaborativo. Em relação a este último, à parte a constante presença do trinômio dramaturgo-diretor-atores, cada equipe desenvolve seu próprio método de trabalho e as pesquisas sobre o processo avançam em número e qualidade. Exemplos que merecem destaque, mas permanecem à margem dos noticiários, são os projetos da Escola Livre de Teatro (ELT) de Santo André, e o Núcleo de Dramaturgia do Grupo Galpão, de Belo Horizonte.

Antonio Araújo vem, há tempos, coordenando estudo e prática do processo colaborativo com os alunos da ELT, da USP e de diversas ofi- cinas culturais. Só em Santo André foram mais de vinte produçóes, originais ou a partir de releitura de obras, em que o diretor do Teatro da Vertigem orientou o trabalho dos diretores, os dramaturgos foram assistidos por Abreu, e os atores tiveram a orientação de Luiz Fernando Ramos e, atualmente, Lucienne Guedes. O atual projeto pretende a releitura de Crime e castigo de Dostoievski e conta com um grupo de aproximadamente 40 pessoas, entre diretores, dramaturgos e atores, trabalhando colaborativamente, distribuídos por equipes e com resultados previstos para dezembro de 2002.

O Grupo Galpão conta, desde 1999, com um Núcleo de Dramaturgia que atua de modo colaborativo para a produção dos espetáculos do chamado Oficinão - curso para atores, com duração média de um ano, e que culmina com a montagem de uma peça dirigida por um componente do Galpão. Criado e coordenado por Luís Alberto de Abreu, o Núcleo está em seu quarto trabalho e, a cada ano, recebe novos interessados em dramaturgia que vão se adaptando ao modus operandi em constante evolução dos veteranos. O próprio Galpão produziu seu mais recente espetáculo, Um trem chamado desejo, nos moldes colaborativos - quase vinte anos depois de suas primeiras experiências com criação coletiva.

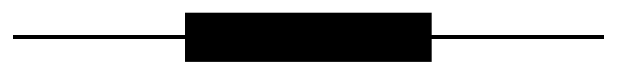

\section{Referências bibliográficas}

ANDRADE, Welington Wagner. O livro de Jó, de Luis Alberto de Abreu; mito e invenção dramática, 2000. 199 p. (Dissertação de mestrado. Universidade de São Paulo)

ARAÚJO, Antonio. E a carne se fez verbo. In: Trilogia biblica. São Paulo: Publifolha, 2002, p. 81-4.

CARVALHO, Sérgio de. A escrita cênica de 'O Paraíso Perdido'. In: Trilogia bíblica. São Paulo: Publifolha, 2002, p. 55-7. 
FERNANDES, Sílvia. Grupos teatrais: anos 70. Campinas: Unicamp, 2000.

. Apontamentos sobre o texto teatral contemporâneo. Sala Preta, São Paulo, v. 1, n. 1, p. 69-79, jun. 2001.

REWALD, Rubens A. Caos/dramaturgia. (Dissertação de mestrado). Universidade de São Paulo, 1998).

PAVIS, Patrice. Dicionário de teatro. São Paulo: Perspectiva, 2000.

RINALDI, Miriam. O que fazemos na sala de ensaio. In: Trilogia bíblica. São Paulo: Publifolha, 2002, p. 45-54.

URBINATTI, Tin. Pensão liberdade: uma criação coletiva. In: GRUPO DE TEATRO FORJA. Pensão liberdade. São Paulo: Hucitec, 1981. 